\title{
New considerations on the kinetics of mass transfer in sodium fast reactors: an attempt to consider irradiation effects and low temperature corrosion.
}

Laurent Brissonneau

CEA, DEN, DTN/STPA/LIPC, Cadarache, F-13108 Saint-Paul-lez-Durance, France, Tel : (33)442 254258 ; Fax (33)442 257287 ; laurent.brissonneau@cea.fr

\begin{abstract}
Mass transfer in sodium fast reactors (SFR) has been extensively studied in the past years, but no consideration on the effect of irradiation on this phenomenon was included in the corrosion equations. Moreover, some discrepancies exist on the mass loss rates obtained at low temperatures and low oxygen content. In this paper, new equations for mass loss are proposed from literature examination, separating the loss by preferential leaching (alloy element dissolution) from general corrosion, and integrating the effect of the diffusion enhancement by irradiation. The effect of irradiation is considered by estimating the diffusion coefficient enhancement due to point defect creation. It is found that the mass losses could be one order of magnitude higher than the values given by several mass transfer models. Depending on the choice of kinetic parameters, the irradiation can account at the most for $70 \%$ of the increase. This approach shows that mass transfer codes should take into account elements that were formerly neglected: low temperature corrosion (with correct contributions of preferential leaching and general corrosion), irradiation and saturation.
\end{abstract}

Keywords: SFR ; mass transfer ; corrosion ; irradiation ; diffusion

\section{Introduction}

Mass transfer in sodium fast reactors (SFR) has been extensively studied by American, European and Japanese teams [1]. The driving force for mass transfer is the difference of solubility of the elements of the steel components in the hot and the cold parts of the reactor (only this driving force has to be considered as the materials are similar in the hot and the cold parts [2]). In hot parts, steel claddings are corroded, the dissolved elements are transported into the sodium and deposited in the cold parts such as the intermediate heat exchanger (IHX), the primary pumps (PP) or the lower part of the core. The temperature of the sodium varies typically from $390^{\circ} \mathrm{C}$ to $550^{\circ} \mathrm{C}$ in the core and the hottest points on the claddings can be at $650^{\circ} \mathrm{C}$. As the solubility of an element depends on the temperature, the limit between hot and cold zones will depend on the regarded element. The mass transfer can affect the operation of the reactor in different ways:

- Corrosion may lead to a decrease of the mechanical integrity of the claddings.

- Deposits on the intermediate heat exchanger may lead to its fouling: loss in the efficiency of the heat transfer between the primary and secondary circuits.

- Deposits of radionuclides can lead to high levels of contamination on the components, which have to be addressed during the maintenance or dismantling operations, the main radio-contaminants being ${ }^{54} \mathrm{Mn}$ and ${ }^{60} \mathrm{Co}[3-5]$. 
Operating conditions such as low oxygen content are usually chosen so that the corrosion rate is slow enough to preserve the mechanical integrity of the claddings and fouling was never observed yet in a SFR (nevertheless long term operations at nominal power are rare, as discussed at the end of the paper). But contamination assessment is of major interest for maintenance and dismantling operations. From the past experience of maintenance operations on heat exchangers or other components, effective contamination data were obtained from spectroscopy measurements, contamination sample analysis or decontamination operations [4]. However, the assessment of conservative values for operational dosimetry at different times and locations in the reactor would be appreciated. With this perspective, a mass transfer code should take into account the different phenomena related to corrosion and deposition, and especially the solubility limits of the elements. The ANACCONDA code developed in the French Atomic Energy Commission (CEA), provides release values but does not deal with the deposition aspects [6]. These latter phenomena are treated in the Japanese code PSYCHE [5], based on Polley\&Skyrme modelling of mass transfer in sodium [7], taking into account the equilibrium concentration of the elements in sodium (instead of an hypothetic zero concentration). In this paper, we discuss two points that might have been underestimated in previous release kinetic analysis: the corrosion at low temperatures and the irradiation effect on release kinetics.

It should be emphasized that mass transfer in SFR has been assessed as a consequence of the corrosion of the claddings, through the results of corrosion kinetics that are mainly based on sodium loop experiments. For this reason, the effects of corrosion at mild temperatures (release below $600^{\circ} \mathrm{C}$ on the pin surface in the core) were not extensively studied, as they are hard to evidence by corrosion specimen examination. As well, irradiation effects have never been taken into account, though some authors noticed that it could be of importance, as the defects produced by irradiation might enhance the diffusion process [8, 9].

However, due to the large areas of claddings at mild temperatures compared to those at high temperatures $\left(\mathrm{T}>600^{\circ} \mathrm{C}\right)$, the mass transfer might be highly underestimated [10]. Moreover, at mild temperatures, the irradiation enhances diffusion and should then increase the release of the most soluble species (preferential leaching added to the loss due to the general corrosion). Considering this, it seems that it would be of interest to give some first answers to the following questions:

- Does the low temperature corrosion should be taken into account in mass transfer?

- Does the irradiation deeply influence the kinetics of diffusion of these species?

- What is the influence of the ferritic layer formed by loss of nickel nearby the surface on the flow of preferentially leached species (especially $\mathrm{Mn})$ ?

In a first part of this paper, mass transfer assessments are performed by separating the different corrosion contributions in the case of low oxygen content and low temperatures. Then the effect of irradiation is estimated by calculating the enhancement of the diffusion coefficients due to the creation of point defects and is then implemented in the mass transfer assessments.

\section{Mass transfer assessments in an SFR}

\subsection{Phenomenology}


Two mechanisms are driving the corrosion of the claddings in sodium [11]:

- The direct dissolution of elements in the sodium (loss limited by diffusion in the metal, also called "preferential leaching"). This is particularly relevant for elements with large solubility in sodium: nickel, manganese, chromium, silicon. The steel surface is locally depleted in these elements that are preferentially leached in the sodium. When the nickel concentration is low enough, a layer of ferrite is formed on the surface of the steel in contact with the sodium. In loop experiments, the thickness of the layer increases with the temperature of the claddings. It is accepted that the leaching of nickel, chromium and manganese is limited by their rate of diffusion in the steel.

- The iron removal occurring at steel/sodium interface (called "surface reaction" or "general corrosion" further in the text), which leads to the surface recession. The reaction rate depends on the oxygen content in the sodium. At high oxygen content, ternary oxide compounds can be stable and removed by process of corrosion/erosion [12]. At low oxygen content (less than $3 \mathrm{ppm}$ ), there is apparently no formation of oxide compounds (as confirmed by thermodynamic calculations [13]); it is thus possible to consider that oxygen acts as a catalyst of the iron dissolution $[11,12]$. All other alloy elements are removed with the iron, as iron is the major element of the steel structure. This mechanism might be the only way of dissolution of the elements with a low solubility in sodium (like Mo or Co).

It should be underlined that this is of course a simplified view of the phenomena. Surface of steels submitted to corrosion in sodium exhibits also particular roughness, where porosities are poorer in leached elements (nickel, manganese) [14]. Both phenomena contribute to mass loss but the rate of general corrosion (iron dissolution) should stay constant with time whereas the mass loss by preferential leaching should decrease with time (because of the surface depletion of leached elements), until the thickness increase of the depleted zone is compensated by the surface removal. Hence, the mass loss is maximum at the beginning when the preferential leaching is more favoured (because of higher concentration gradients) and then decreases with time until it reaches a limit value that depends on the diffusion coefficients of the leached species and the surface reaction rate. However, following the analysis of Anno and Wallowit [15], if the general corrosion rate is low enough, so that the losses by diffusion and general corrosion are not coupled, the mass loss can be expressed as:

$\Delta m=k_{1} \sqrt{t^{\prime}}+k_{2} t$

where the first right hand term represents the loss by preferential leaching and the second one by general corrosion, $\mathrm{k}_{1}$ and $\mathrm{k}_{2}$ are reaction rate constants (independent of time) for the loss by preferential leaching and general diffusion, respectively.

For a particular element $A$, the surface mass loss $S_{A}$ by preferential leaching can be expressed as:

$S_{A}=\rho C_{A} \cdot\left(D_{A} \cdot t / \pi\right)^{1 / 2}$

the symbols are defined in Table $5, D_{A}$ is the diffusion coefficient of element $A$ in the steel (in $\left.\mathrm{cm}^{2} \cdot \mathrm{s}^{-1}\right)$. Such an analysis is used in the French Code ANACCONDA for 
mass transfer [6], but the expression may be more complex, as diffusion coefficients are different in austenite and ferrite.

It is obvious that the enhancement of the diffusion by irradiation might greatly affect the preferential leaching and should not influence the surface reaction rate. Indeed, it can be considered, as did by Anno \& Wallowit [15], that atom sputtering at the surface might lead to their dissolution in sodium; they estimated about $40 \mu \mathrm{m}^{-y^{-1}}$ for 100 dpa. $^{-1}$ which is one order of magnitude higher than what is observed for thickness removal in reactor [14]. Moreover, they consider a sputtering ratio that appears to be very high when compared to the number of displaced atoms, 100 atoms per year, which correspond to a removed thickness of about $30 \mathrm{~nm}$ (assuming that each displaced atom of the surface is actually transferred into the sodium). We then deduce that the applied sputtering ratio is not correct in this assumption. Hence, in the following, we shall only consider the effect of irradiation on the enhancement of the preferential leaching, which is of particular meaning as the most contributing species to the contamination of the components in the cold legs are ${ }^{54} \mathrm{Mn}$ and to a lesser extent ${ }^{51} \mathrm{Cr}$ [16] ( $\mathrm{Mn}$ and $\mathrm{Cr}$ are mainly removed by preferential leaching).

\subsection{Mass losses according to classical relationships}

According to experiments in sodium loops, the iron removal is very slow at temperatures below $550^{\circ} \mathrm{C}$, especially at low oxygen content $(<3 \mathrm{ppm})$. By instant, an empirical law is used in ANACCONDA code, which best reproduces Baqué's results $[6,10]$ :

$$
S=7.8 \cdot v^{0,435} \cdot[O] \cdot \exp \left(\frac{-150,5}{\theta-544}\right)
$$

The mass loss $\mathrm{S}$ (in mg. $\mathrm{cm}^{-2} \cdot \mathrm{y}^{-1}$ ) being a function of the sodium velocity in the core $v$ (in $\mathrm{m}^{-1} \mathrm{~s}^{-1}$ ), the oxygen content [O] (in ppm) and the temperature $\theta$ (in ${ }^{\circ} \mathrm{C}$ ). For this author, it has no meaning to calculate the mass loss at temperatures lower than $544^{\circ} \mathrm{C}$ and so this correlation can only be applied for temperatures higher than this lower value. This form of equation was originally proposed by General Electrics [1]. It should be underlined that this equation takes into account both the mass loss by surface reaction and preferential leaching for one year of corrosion.

For oxygen content higher than $5 \mathrm{ppm}$, the ANACCONDA code used the "modified" Thorley's law [10], equation (4). The modification takes into account different ways of calculating oxygen content in the sodium by different authors, as different oxygen solubility curves were chosen (as a function of cold trap temperatures). For ANACCONDA, the Eichelberger's law [17] for oxygen solubility is preferred. As a consequence, the correlation (4) expresses the modified Thorley's law, using the Noden's equation for the oxygen solubility (consequently when Thorley reported 10 ppm in his papers, it corresponds to 4 ppm in equation (4) with the Eichelberger's law for the same cold trap temperature).

$$
\log _{10} S=4.724+1.106 \cdot \log _{10}[O]-\frac{3913}{T}
$$

where $S$ is the release rate in $\mu \mathrm{m} . \mathrm{y}^{-1},[\mathrm{O}]$ is the oxygen concentration in ppm and $\mathrm{T}$ the temperature in Kelvin.

In Japan [18], the original Thorley's equation is used, though only valid at oxygen concentration higher than $5 \mathrm{ppm}$. At lower concentrations, the corrosion rate is estimated by using the limit value of 5 ppm. However, as it has just been mentioned, 
$5 \mathrm{ppm}$ of oxygen in Thorley's equation might correspond in fact to $1.6 \mathrm{ppm}$ when applying Eichelberger's law. The use of Thorley's law could lead to large overestimation of the mass transfer, while using the Baqué's equation leads to underestimation due to the neglect of the lower temperature contribution. For an oxygen content of $1.6 \mathrm{ppm}$ at $550^{\circ} \mathrm{C}$ and $600^{\circ} \mathrm{C}$, the use of Baqué's law leads to corrosion rate of 0 and $2.65 \mu \mathrm{m} . \mathrm{y}^{-1}$ respectively, when equation (4) yields $1.4 \mu \mathrm{m} . \mathrm{y}^{-1}$ and 2.65 $\mu \mathrm{m} \cdot \mathrm{y}^{-1}$. Then, at higher temperatures, the use of Baqué's law leads to much higher corrosion rates than equation (4).

By applying Baqué's equation (3) for the mass loss, it is possible to calculate the mass transfer in a SFR like Superphénix, as already proposed in [10] where most of the conditions of the calculations can be found. The material of the claddings is 316 steel, the temperature variation in the core is between $390^{\circ} \mathrm{C}$ and $545^{\circ} \mathrm{C}$, a typical velocity of $8 \mathrm{~m} . \mathrm{s}^{-1}$ for the sodium in the core was chosen for all the calculations performed in the paper. In Superphénix, about half of the surfaces have temperatures between 390 and $450^{\circ} \mathrm{C}$. Mild and hot surfaces exhibit an approximately uniform distribution between 450 and $580^{\circ} \mathrm{C}$, the area of hot surfaces decreases rapidly above $580^{\circ} \mathrm{C}$, up to $630^{\circ} \mathrm{C}$ (about $2 \%$ of the total area of the core). We reported in first column of Table 1 the total corroded mass in one year for three oxygen contents: $0.7,1$ and $3 \mathrm{ppm}$. We also reported the mass loss calculated by using the modified Thorley's equation (4), though the equation should be better used at oxygen content higher than $5 \mathrm{ppm}$ (second column). The four last columns of Table 1 yield results that will be discussed in $\S 2.5$.

\begin{tabular}{|l|l|l|l|l|l|l|l|}
\hline $\begin{array}{l}\text { Mass loss } \\
\left(\begin{array}{l}\mathrm{kg}_{\mathrm{year}}^{-1} \text { ) } \\
\text { at } \neq \mathrm{O}]\end{array}\right.\end{array}$ & Baqué & Thorley & $\begin{array}{l}\text { Thorley } \\
\text { HT }\end{array}$ & $\begin{array}{l}\text { Eq.9 } \\
\text { set 1 }\end{array}$ & $\begin{array}{l}\text { Eq.9 } \\
\text { set 2 }\end{array}$ & $\begin{array}{l}\text { Eq.9 } \\
\text { +irrad. } \\
\text { Set1 }\end{array}$ & $\begin{array}{l}\text { Eq.9 } \\
\text { +irrad. } \\
\text { Set2 }\end{array}$ \\
\hline $0.7 \mathrm{ppm}$ & 2.4 & 18.0 & 13.7 & 16.2 & 15.5 & 50.5 & 81.8 \\
\hline $1 \mathrm{ppm}$ & 3.4 & 26.7 & 20.3 & 20.6 & 18.4 & 54.9 & 84.7 \\
\hline $3 \mathrm{ppm}$ & 10.1 & 89.8 & 68.3 & 49.7 & 37.7 & 84 & 104 \\
\hline
\end{tabular}

Table 1 : Calculated mass loss after one year in Superphénix for different oxygen contents in sodium according to different assumptions on corrosion.

The much lower mass losses when using Baqué's equation compared to results with Thorley's equation are explained by the corrosion of the surfaces at low and mild temperatures, that is considered in Thorley's equation and not in Baqué's one (limited to temperatures above $544^{\circ} \mathrm{C}$ ) [10]. Even if a factor of 2 or 3 might be acceptable for estimated mass loss, the discrepancies are here in an order of magnitude. As a consequence, a better assessment of the corrosion rate at low temperatures and low oxygen contents seems necessary.

First, a temperature limit for the calculation of the mass loss should be estimated, that might give a better agreement than the temperature of $544^{\circ} \mathrm{C}$ proposed by Baqué.

It should be remembered that the driving force for both corrosion mechanism is the difference of activity for the element between the solid phase (cladding composition) and the liquid phase (concentration of dissolved elements in sodium). At low temperatures, the solubility of the elements in sodium is very low, excepting the silicon (see for example [19] for the solubility of main elements between 300 and $800^{\circ} \mathrm{C}$, data are reported in Figure 1). 
Elements are dissolved in the hot parts of the sodium flow (upper part of fuel pins corresponding to the core outlet), but their concentration becomes higher than the solubility limit in the cold parts, such as the lower part (outlet) of the intermediate heat exchanger, the primary pump and the lower part (inlet) of the core, if the deposition rate on the former surfaces is slow enough. Similarly, a "downstream effect" can be observed on the hot surface at the upper parts of the core if enough quantity of element was dissolved upstream. These two saturation effects were observed on irradiated 316 claddings in JOYO (as shown in Figure 2) and PHENIX [14]. At temperatures lower than $480^{\circ} \mathrm{C}$, particles enriched in nickel and manganese are deposited on the cold part of the claddings, then the pins are depleted in nickel and manganese ) in intermediate part of the core at temperatures upper than $500^{\circ} \mathrm{C}$ (ferritization is observed, and chromium at temperatures upper $550^{\circ} \mathrm{C}$. But at the upper part of the pins, nickel and chromium depletions decrease due to "the downstream effect". As the solubility limit of silicon in sodium is very large, this element is always removed at any length of the pin, whatever its temperature. For our purpose, one important conclusion can be drawn: the behaviour of the elements might be completely different according to their solubility in sodium; the mass transfer modelling should consider the element concentration in the sodium as a determinant parameter for the partition of corrosion and deposition zones (not only parted according to their temperature).

However, for simplicity sake, it will be considered in this tentative approach that the temperature limit for the mass transfer is $480^{\circ} \mathrm{C}$, as observed for the pins of JOYO and PHENIX in particular for the nickel. It must be emphasized that the temperature limit might depend on many parameters, the main ones being: the element solubility, the temperature range of the system, the sodium volume, the area of the claddings and components... Limiting the surfaces to those with temperatures above $480^{\circ} \mathrm{C}$, new values are found using Thorley's equation for mass loss in Superphénix (see Table 1, third column). Mild temperatures for the claddings can then be considered to be between $480^{\circ} \mathrm{C}$ and $550^{\circ} \mathrm{C}$. Still, these new values for the mass loss are high and the discrepancy remains with the results obtained from the Baqué's law.

For a better approach, a more sound equation (as Thorley's one is strictly valid for oxygen contents upper $5 \mathrm{ppm}$ ) should be used, that separates the contributions of general corrosion and preferential leaching in the mass loss, as in Eq.(1). This assumption sounds reasonable, as the general corrosion is generally slow at mild temperatures. Moreover, the effect of irradiation will be added in the term of preferential leaching, as it could be highly underestimated at low temperatures due to the enhancement of the diffusion coefficients by radiation induced point defects.

\subsection{Principles of calculations}

In most analyses, the authors give global mass loss equations like equations (3) or (4) and do not really part between mass loss from leaching and general corrosion. Moreover, the temperature dependencies of these two phenomena are not distinguished, but apparent activation energy for the global process is given. However, it is generally admitted that the leaching process is limited by diffusion in the steel, i.e. the apparent activation energy of this process is half of the usual activation energy characteristic of the diffusion coefficient in the steel, as the mass loss is related to the square root of this diffusion coefficient [8], as noted in Eq.(2). To integrate the effect of irradiation, it is necessary to have separate release contributions for general corrosion and preferential leaching at low oxygen values 
and low temperatures. However it will be seen that though apparently close, the difference of mass loss between authors can lead to rather dissimilar mass transfer assessments. Then, in the next paragraph, the contribution from leaching will be obtained by using new diffusion coefficients calculated under irradiation.

\subsubsection{Considerations on sodium corrosion kinetics at low oxygen contents}

Most detailed results concerning in pile results at low oxygen content are for SS316 fuel pins irradiated in JOYO or PHENIX during 7100 and 13580 hours [14], 1 ppm of oxygen. Thickness measurements yield a global corrosion rate of $2 \mu \mathrm{m} . \mathrm{y}^{-1}$ at $600^{\circ} \mathrm{C}$, which corresponds to $1.6 \mathrm{mg} \cdot \mathrm{cm}^{-2} \cdot \mathrm{y}^{-1}$. The measurements are said to be within the range of out-of-pile measurements, which are rather scarce, from 1.5 to $3 \mu \mathrm{m} . \mathrm{y}^{-1}$ at $600^{\circ} \mathrm{C}$. According to the authors, the thickness loss corresponding to the decrease in concentration (preferential leaching) of alloying elements was estimated to be 0.3 $\mu \mathrm{m} . \mathrm{y}^{-1}$. However, preferential leaching should not lead to surface recession, and considering ferrite thickness and profile concentration, release corrosion seems underestimated. By considering the ferrite thickness (preferential release zone), its composition (see Figure 2) and the surface recession, it could rather be assessed that the mass loss by diffusion was about $0.8 \mathrm{mg} \mathrm{cm}^{-2} \mathrm{y}^{-1}$ and the mass loss by general corrosion about $1.5 \mathrm{mg}^{\mathrm{cm}} \mathrm{cm}^{-2} \mathrm{y}^{-1}$ (a thickness of $1.9 \mu \mathrm{m}$ ). In general, the lower bound of their out-of-pile results fits with the Baqué's equation (see Figure 3 ). These results will be compared with corrosion in loop results, which for mass loss equations describing both general corrosion and leaching corrosion are available (see Table 2).

Brehm et al. [8] proposed very interesting mass loss equations, differentiated according to main elements at $538^{\circ} \mathrm{C}$ and $604^{\circ} \mathrm{C}$ at $0.5 \mathrm{ppm}$ and 2.5 of oxygen, i.e. at conditions where the surface reaction rate is very slow:

$\mathrm{S}_{\mathrm{B}}=1.15 . \mathrm{t}_{\mathrm{B}}+1.26$ at $604^{\circ} \mathrm{C}$; total corrosion at $0.5 \mathrm{ppm} \mathrm{O}$

$\mathrm{S}_{\mathrm{B}}=2.86 . \mathrm{tB}_{\mathrm{B}}+0.27$ at $604^{\circ} \mathrm{C}$, total corrosion at $2.5 \mathrm{ppm} \mathrm{O}$

$\mathrm{S}_{\mathrm{B}}=0.14 . \mathrm{tB}_{\mathrm{B}}+1.26$ at $604^{\circ} \mathrm{C} 0.5 \mathrm{ppm} \mathrm{O}$ for iron only

$\mathrm{S}_{\mathrm{B}}=1.28 . \mathrm{t}_{\mathrm{B}}-0.87$ at $604^{\circ} \mathrm{C} 2.5 \mathrm{ppm} \mathrm{O}$ for iron only

where the mass loss $S_{B}$ is in $\mu \mathrm{g} \cdot \mathrm{mm}^{-2}$ and the $t_{B}$ is the time in thousand hours.

Following equations (6), the global mass loss is linear with time; by comparing to equation (1), it could be concluded that mass loss by general corrosion is predominant at these temperatures (between $538^{\circ} \mathrm{C}$ and $604^{\circ} \mathrm{C}$ ). However, this is rather inexact at short times. In one year, considering that the general corrosion is correlated to iron mass loss, it can be seen by comparing Eq.(6a) and Eq.(7a) at $604^{\circ} \mathrm{C}$ and $0.5 \mathrm{ppm}$ oxygen, that the general corrosion would only lead to about $1 / 4$ of the total mass loss in one year (Eq.(6a): $1.13 \mathrm{mg} . \mathrm{cm}^{-2}$; Eq. (7a): $0.25 \mathrm{mg}^{-\mathrm{cm}^{-2}}$ ). The authors also proposed logarithmic correlations for their mass loss results. Surprisingly, these correlations result in the same exponent for nickel or iron, 0.71 , intermediary between 1 expected for iron (loss only by general corrosion, second term of equation 1) and 0.5 expected for nickel (loss mainly by preferential release limited by diffusion, first term of equation 1). Finally, in these experiments, the authors found clearly a value of one for the oxygen content exponent.

To our opinion, it should be concluded that both mechanisms, general corrosion and preferential leaching, are operating at equivalent levels for the mass loss at durations typical of claddings time past in the reactor (few years). It could be estimated by linear interpolation of Eq.(6a) and Eq.(6b) that the mass loss at $600^{\circ} \mathrm{C}$ and $1 \mathrm{ppm}$ 
oxygen would be $1.5 \mathrm{mg} \cdot \mathrm{cm}^{-2} \mathrm{y}^{-1}$ with $0.45 \mathrm{mg}^{\mathrm{cm}} \mathrm{cm}^{-2} \mathrm{y}^{-1}$ for general corrosion (combination of Eq.(7a) and Eq.(7b) ) and then $1.05 \mathrm{mg}^{\mathrm{cm}} \mathrm{cm}^{-2} \mathrm{y}^{-1}$ for leaching.

Using Baqué's equation (3), at $600^{\circ} \mathrm{C}$ and $1 \mathrm{ppm}$ oxygen, the mass loss in one year is $1.3 \mathrm{mg} \cdot \mathrm{cm}^{-2}$. Because of the particular form of equation (3), the results are greatly dependant of temperature between $550^{\circ} \mathrm{C}$ and $620^{\circ} \mathrm{C}$. At $600^{\circ} \mathrm{C}$ and $0.7 \mathrm{ppm}$ of oxygen, Baqué [20] estimated from mass loss and metallographic observations that $0.92 \mathrm{mg} . \mathrm{cm}^{-2}$ are lost in one year, with $0.4 \mathrm{mg} . \mathrm{cm}^{-2}$ mass loss due to leaching and $0.52 \mathrm{mg} . \mathrm{cm}^{-2}$ from general corrosion; it could then be assessed, considering oxygen dependency in relation (3), that the mass loss for general corrosion at $600^{\circ} \mathrm{C}$ and 1 ppm oxygen is about $0.75 \mathrm{mg}_{\mathrm{cm}}^{-2} \mathrm{y}^{-1}$ and then the one for leaching is $0.55 \mathrm{mg} . \mathrm{cm}^{-2}$ $\mathrm{y}^{-1}$ (the increase of the leaching corrosion with oxygen content denotes that the two phenomena are in fact coupled).

Baqué found no mass loss under $550^{\circ} \mathrm{C}$ when at $538^{\circ} \mathrm{C}$ Brehm was able to quantify it. The global mass loss at $600^{\circ} \mathrm{C}$ and $1 \mathrm{ppm}$ oxygen are close for both authors, but for another oxygen content or at a higher or lower temperature, it could have been much different. For example at $0.5 \mathrm{ppm}$ oxygen and $604^{\circ} \mathrm{C}$ (equation $6 \mathrm{a}$ ) the mass loss is $1.13 \mathrm{mg} . \mathrm{cm}^{-2} \mathrm{y}^{-1}$ for Brehm when it is $0.80 \mathrm{mg} \cdot \mathrm{cm}^{-2} \mathrm{y}^{-1}$ according to Eq.(3), $30 \%$ lower. Very surprising is also that the general corrosion at $600^{\circ} \mathrm{C}$ and $1 \mathrm{ppm} \mathrm{O}$ is much different (higher for Baqué), though similar global rates are assessed and that similar ferrite layer thicknesses are observed (which is related to the loss by leaching).

Kolster proposed a two terms equation [21] that separates leaching contribution and general corrosion contribution (in fact instead of general corrosion, Kolster talked about steady-state corrosion, the difference will be treated in the discussion):

$$
S_{s t}=1.2 \cdot 10^{11} \cdot \exp \left(\frac{-203 \cdot 10^{3}}{\mathfrak{R} \cdot T}\right)+3.8 \cdot 10^{2} \cdot[O] \cdot \exp \left(\frac{-58.6 \cdot 10^{3}}{\mathfrak{R} \cdot T}\right)
$$

the mass loss $\mathrm{S}_{\text {st }}$ is expressed in $\mathrm{mg} \cdot \mathrm{cm}^{-2} \cdot \mathrm{y}^{-1}$. The oxygen dependency exponent is one. The first right hand term accounting for dissolution by leaching was determined by magnetic measurements of residual ferrite. Borgstedt [22] compared different kinetic laws and experimental results and identified that the Kolster's equation could be used in low oxygen content cases. As the experiments were run at 1, 1.5 and 3 ppm at $650^{\circ} \mathrm{C}$ and $700^{\circ} \mathrm{C}$, the equation should be valid in our case of interest (low oxygen content). However, by applying equation (8) at $600^{\circ} \mathrm{C}$ and $1 \mathrm{ppm} \mathrm{O}$, it results in a mass loss of only $0.09 \mathrm{mg} . \mathrm{cm}^{-2}$ in one year for preferential leaching and 0.12 $\mathrm{mg} . \mathrm{cm}^{-2}$ for general corrosion. These are rather low results compared to others and it could be due to the values attributed to activation energies, which have been determined by experiments at only two temperatures.

Brehm et al. found that an apparent activation energy of $150 \mathrm{~kJ} \cdot \mathrm{mol}^{-1}$ could be used to reproduce their own global results, and $98 \mathrm{~kJ} \mathrm{~mol}^{-1}$ for the leaching process (here ${ }^{54} \mathrm{Mn}$ release) in accordance with the diffusion of $\mathrm{Mn}$ in grain boundaries of 304 steel. This high activation energy for global corrosion, compared to results published by other authors, might be related to the fact that the loss by leaching are much higher for Brehm than by general corrosion, with respect to other corrosion loop experiments. According to the particular form of the equations of Baqué, no activation energy can be deduced, but Borgsted [22] proposed an interpretation of Baqué's 
results with an activation energy of $92 \mathrm{~kJ}_{\mathrm{mol}}{ }^{-1}$. The activation energy proposed by Kolster for the general corrosion is rather low: $58.6 \mathrm{~kJ} \mathrm{~mol}^{-1}$.

In other studies, the activation energies might vary from 75 to $107 \mathrm{~kJ}^{-\mathrm{mol}^{-1}}$ [22], but are often related to high oxygen content experiments and both include leaching contribution (which is supposed to have a high activation energy related to bulk diffusion, but might be reduced by grain boundary diffusion [8]) and general corrosion (with a lower activation energy). An activation energy for the general corrosion was proposed to be $92 \mathrm{~kJ} \mathrm{~mol}^{-1}$ by Maruyama et al. (cited in [23]) It should be noticed that Maruyama's equation has been compared favourably with other authors and is the reference equation for the Japanese code PSYCHE.

For in pile claddings at $600^{\circ} \mathrm{C}$, the ferrite thickness is $4 \mu \mathrm{m}$ in less than one year [14]. Baqué and Brehm reported a ferrite thickness of $2 \mu \mathrm{m}$ in one year, which is lower and would confirm that the mass loss by diffusion is higher under irradiation. In fuel pins irradiated in EBR-II, at $1 \mathrm{ppm}$ oxygen but with higher temperature conditions and

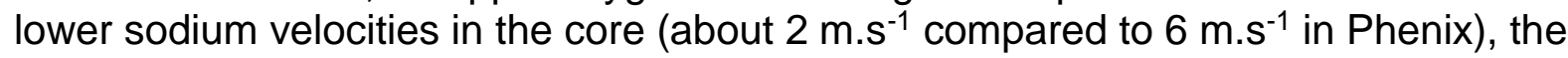
ferrite thickness was found to increase from $1 \mu \mathrm{m}$ at $560^{\circ} \mathrm{C}-590^{\circ} \mathrm{C}$ to $3 \mu \mathrm{m}$ at 650 $675^{\circ} \mathrm{C}$. The corrosion rate at $700^{\circ} \mathrm{C}$ was estimated between 6 and $10 \mu \mathrm{m} . \mathrm{y}^{-1}$, which is in agreement with equation (3) [24]. These particular results under irradiation will be also discussed later.

The data for the corrosion rates at low temperatures for different authors are compiled in Table 2 for sake of comparison.

\begin{tabular}{|c|c|c|c|c|}
\hline & Brehm & Baqué & Kolster & Ukai \\
\hline $\begin{array}{l}\text { Total corrosion } \\
\left(\mathrm{mg}_{\mathrm{cm}} \mathrm{cm}^{-2} \cdot \mathrm{y}^{-1}\right)\end{array}$ & 1.5 & 1.3 & 0.21 & $1.6-2.4$ \\
\hline $\mathrm{E}_{\mathrm{A}}\left(\mathrm{kJ} . \mathrm{mol}^{-1}\right)$ & 150 & - & & \\
\hline $\begin{array}{l}\text { General corrosion } \\
\left(\mathrm{mg} \cdot \mathrm{cm}^{-2} \cdot \mathrm{y}^{-1}\right)\end{array}$ & $0.45^{\star}$ & $0.75^{\star}$ & 0.12 & $1.5^{\star}$ \\
\hline $\mathrm{E}_{\mathrm{A}}\left(\mathrm{kJ} \cdot \mathrm{mol}^{-1}\right)$ & & - & 58.6 & \\
\hline $\begin{array}{l}\text { Leaching corrosion } \\
\left(\mathrm{mg} \cdot \mathrm{cm}^{-2} \cdot \mathrm{y}^{-1}\right)\end{array}$ & $1.05^{\star}$ & $0.55^{\star}$ & 0.09 & $0.8^{*}$ \\
\hline $\mathrm{E}_{\mathrm{A}}\left(\mathrm{kJ} . \mathrm{mol}^{-1}\right)$ & 98 & - & 203 & \\
\hline
\end{tabular}

* estimated

Table 2 : Global mass loss and contributions by general and leaching corrosion assessed from different authors at $600^{\circ} \mathrm{C}$ and $1 \mathrm{ppm} 0$.

\subsubsection{Mass loss equation at low temperatures and low oxygen contents}

As a consequence of this short literature survey, it is difficult to find sound values for leaching and general corrosion at low oxygen content and low temperatures, though all authors found results in the same order of magnitude. The reasons for these discrepancies could be:

- a bad assessment of the oxygen dependency exponent for the general corrosion: this is however dubious, since Brehm et al. results [8] show clear linear dependency of the iron release with the oxygen content. 
- an effect of the sodium saturation with released elements, that might affect the corrosion rate. However, in the case of the results of Brehm et al.[8] the saturation would have affected the general corrosion rate (iron saturation), which is slow, when in the case of the results of Baqué, it would have affected the leaching corrosion rate $\left(0.55 \mathrm{mg} \cdot \mathrm{cm}^{-2} \cdot \mathrm{y}^{-1}\right.$ compared to 1.05 for Brehm et al.).

In order to perform our calculation, the form of the equation (8) was kept but two other sets of coefficients were considered, which would approximately fit corrosion results of Baqué or Brehm et al. respectively for the first and second set in Table 3. The activation energy for the leaching (first right hand) term is taken near half of the one of diffusion coefficient of iron in austenite (according to the form of Eq.(2) in $\sqrt{ } \mathrm{D}$ ) and the one for the general corrosion (second right hand) term is taken as an average of published values. The values obtained for the general corrosion are bounding the equation proposed by Maruyama et al [23], which means that the chosen sets of parameters are reasonable. The oxygen exponent was chosen as 1 , though Thorley suggested that the value of the exponent might depend on the iron concentration on the surface, the higher, the closer the exponent would be from 2 [12]. However, in Brehm's experiments at low oxygen content, an exponent of 1 seems consistent with the results, though the surface of the steel is depleted in alloying elements. The mass loss equation (in mg. $\mathrm{cm}^{-2} \cdot \mathrm{y}^{-1}$ ) can finally be expressed as follows:

$$
S_{s t}=A_{d i f f} \cdot \exp \left(\frac{-E_{\text {diff }}}{\mathfrak{R} \cdot T}\right)+A_{g e n} \cdot[O] \cdot \exp \left(\frac{-E_{g e n}}{\mathfrak{R} \cdot T}\right)
$$

\begin{tabular}{|l|l|l|l|l|}
\hline & $A_{\text {diff }}$ & $E_{\text {diff }}$ & $A_{\text {gen }}$ & $E_{\text {gen }}$ \\
\hline First set & $1.2 \times 10^{7}$ & $123 \mathrm{~kJ}_{\mathrm{mol}}{ }^{-1}$ & $3.5 \times 10^{5}$ & $92.5 \mathrm{~kJ} \cdot \mathrm{mol}^{-1}$ \\
\hline Second set & $1.0 \times 10^{8}$ & $135 \mathrm{~kJ} \cdot \mathrm{mol}^{-1}$ & $5.0 \times 10^{4}$ & $82 \mathrm{~kJ} \cdot \mathrm{mol}^{-1}$ \\
\hline
\end{tabular}

Table 3 : sets of coefficients of equation (9) use to reproduce the experimental results from Baqué [20] or Brehm et al. [8] for a mass loss $S$ in $\mathrm{mg} \cdot \mathrm{cm}^{-2} \cdot \mathrm{y}^{-1}$. 
In Figure 3, the mass loss is plotted as a function of the temperature for the different contributions and the two sets of coefficients for an oxygen content of $1 \mathrm{ppm}$.

The calculated mass losses are in rather good agreement with the loop experimental results at low temperature. The two sets of equation give close results for total mass loss at $1 \mathrm{ppm} O$, though their respective contributions are quite different. The mass loss at $538^{\circ} \mathrm{C}$ is higher than in Brehm's results, but it was not possible to match both low and high temperature mass losses with the two sets that were used in equation (9).

\subsection{Influence of irradiation on the kinetics of diffusion 2.4.1 Principles of calculation}

The irradiation creates atomic displacements in the materials that result in the production of point defects, vacancies and interstitials (dumbbells). The coefficient of diffusion $\mathrm{D}^{\star}$ of an atom on the main lattice will then be enhanced, according to their concentration $\mathrm{C}$ :

$D^{*}=D_{v} \cdot C_{v}+D_{i} \cdot C_{i}$

where subscript $v$ holds for the vacancies and $i$ for the interstitials, and the diffusion coefficient $D_{d}$ for each defect $(d=i$ or $v)$ is related to the migration energy $E^{m_{d}}$ of the defect:

$D_{d}=D_{d}^{0} \cdot \exp \left(-E_{d}^{m} / \Re \cdot T\right)$

$\Re$ is perfect gas constant and $T$ is the temperature in Kelvin.

Equation (10) is strictly speaking only valid for autodiffusion. In the following, we would then only estimate the effect of the irradiation on the diffusion coefficient of iron in the austenite and the ferrite by calculating the concentrations of point defects at stationary state in a 316 steel and in pure alpha iron respectively, following the method developed by Sizmann [25]. It will be discussed that the results can be reasonably extrapolated to other substitutional elements as $\mathrm{Ni}, \mathrm{Mn}$ or $\mathrm{Cr}$.

The point defects concentration varies as described in equation (12) due to their generation by irradiation at a rate $G$ (in $\left.\mathrm{cm}^{-3} \cdot \mathrm{s}^{-1}\right)$, and their annihilation by mutual recombination ( $2^{\text {nd }}$ right hand term) at rate $B$ or their annihilation on the sinks (dislocations or grain boundary or free surface, $3^{\text {rd }}$ right hand term):

$\left(\frac{\partial C_{d}}{\partial t}\right)=G-B \cdot C_{i} \cdot C_{v}-\left(\frac{\partial C_{d}}{\partial t}\right)_{\text {sinks }}$

The defect production rate $G$ (obtained from Kichin Pease formula) is given by the product of the atomic concentration in the metal by the damage rate in displacement per atom (dpa). In that analysis, the formation of point defect clusters is neglected, as it generally concerns only a limited fraction of defects. If the left hand term is zeroed in equation (12), then it is possible to calculate the steady-state defect concentration (concentration at which their production by neutrons is compensated by their annihilation by recombination or diffusion on sinks).

From Sizmann's analysis, four characteristic times are defined that allow us to determine which annihilation mechanism dominates (recombination or annihilation on sinks) and the time delay to reach steady state. It is then possible to calculate the point defect stationary concentrations, according to the temperature level and sink density. The different combination rate, sink strength, characteristic times and defect 
concentrations were calculated between $350^{\circ} \mathrm{C}$ and $650^{\circ} \mathrm{C}$ in stainless steel and ferrite steel ( $\alpha$ iron). The details of the calculation are given in Appendix.

\subsubsection{Results on defect concentration and diffusion coefficient under irradiation}

All the characteristic times are very small, which means that the steady-state is very rapidly obtained, typically in less than few minutes. According to Sizmann's analysis, it corresponds to the case where the temperature must be considered as low and the sink density as intermediate for alpha iron and low for 304 steel. In both cases, the defect concentrations are given by equation (13):

$$
C_{i}^{s t a t}=\left[\frac{G \cdot D_{v} \cdot k_{v}^{2}}{B \cdot D_{i} \cdot k_{i}^{2}}\right]^{1 / 2} \text { and } C_{v}^{\text {stat }}=\left[\frac{G \cdot D_{i} \cdot k_{i}^{2}}{B \cdot D_{v} \cdot k_{v}^{2}}\right]^{1 / 2}
$$

Where $\mathrm{k}^{2} \mathrm{~d}$ are the sink strengths for the dislocations (see Appendix). In each case, the defects are eliminated predominantly by mutual recombination but steady-state is reached when vacancies reach the dislocations. The vacancy concentration varies as the square root of the dose. In the following, only the results obtained at $30 \mathrm{dpa}_{\mathrm{y}} \mathrm{y}^{-1}$ (corresponding to a final dose of $150 \mathrm{dpa}$ in five years) are presented, but it is to be noticed that the dose rate has only a slight (because of a $\mathrm{G}^{1 / 2}$ dependence in Eq.(13) ) influence on the diffusion coefficient under irradiation.

The defect concentrations under irradiation are calculated at different temperatures and compared to equilibrium (without irradiation) values. Some values are reported between $400^{\circ} \mathrm{C}$ and $700^{\circ} \mathrm{C}$ in Table 4 . A classical result is obtained that the point defect concentration is very weakly temperature dependent and slightly decrease with temperature under irradiation. In both steels, the vacancy concentration is far above the interstitial one and is very close to the equilibrium concentration at $700^{\circ} \mathrm{C}$.

\begin{tabular}{|l||l|l|l||l|l|l|}
\hline Temperature & $\alpha$ Fe C $^{\mathrm{E}} \mathrm{v}$ & $\alpha \mathrm{Fe} \mathrm{C}^{\text {irr }} \mathrm{v}$ & $\alpha \mathrm{Fe} \mathrm{C}^{\text {irr }}$ int & $316 \mathrm{C}_{\mathrm{V}} \mathrm{V}$ & $316 \mathrm{C}^{\text {irr }} \mathrm{v}$ & $316 \mathrm{C}^{\text {irr }}$ int \\
\hline $400^{\circ} \mathrm{C}$ & $6.0 \times 10^{-14}$ & $1.4 \times 10^{-8}$ & $4.3 \times 10^{-11}$ & $2.5 \times 10^{-12}$ & $5.7 \times 10^{-7}$ & $4.0 \times 10^{-11}$ \\
\hline $500^{\circ} \mathrm{C}$ & $8.1 \times 10^{-12}$ & $6.5 \times 10^{-9}$ & $4.2 \times 10^{-11}$ & $1.1 \times 10^{-10}$ & $1.3 \times 10^{-7}$ & $6.9 \times 10^{-11}$ \\
\hline $600^{\circ} \mathrm{C}$ & $3.6 \times 10^{-10}$ & $3.7 \times 10^{-9}$ & $4.2 \times 10^{-11}$ & $2.0 \times 10^{-9}$ & $3.6 \times 10^{-8}$ & $1.1 \times 10^{-10}$ \\
\hline $700^{\circ} \mathrm{C}$ & $7.2 \times 10^{-9}$ & $2.3 \times 10^{-9}$ & $4.1 \times 10^{-11}$ & $2.1 \times 10^{-8}$ & $1.6 \times 10^{-8}$ & $1.5 \times 10^{-10}$ \\
\hline
\end{tabular}

Table 4: Equilibrium vacancy concentration (per atom of iron) and vacancy and interstitial concentrations under irradiation (30 dpa. $\mathrm{y}^{-1}$ ) in alpha iron and 316 steel.

The substitutional diffusion will be enhanced, and so will be the global diffusion phenomena. New iron diffusion coefficients under irradiation can be calculated from equations (10) and (11). They are plotted in Figure 4 and compared with the diffusion coefficients at equilibrium.

Under irradiation, the diffusion coefficient only varies with less than a factor 20 between $400^{\circ} \mathrm{C}$ and $650^{\circ} \mathrm{C}$, while it varies within at least six orders of magnitude at equilibrium in the same temperature range. Hence, all the diffusion related mechanisms that could be neglected at mild temperatures without irradiation should 
be taken into account under irradiation. The diffusion coefficient in ferrite is still higher than in austenite, though the gap between them is lower than at equilibrium.

Very similar results are found for irradiation flow of 10 dpa. $^{-1}$ and 100 dpa. $^{-1}$. It can then be concluded that the results obtained for irradiation effect on mass transfer will only slightly depend on the dose received by the claddings.

\subsubsection{Calculations of the mass flow under irradiation}

For the leaching corrosion, the diffusion flow is proportional to the square root of the diffusion coefficient (see Equation (2) or ref. [15]). The diffusion coefficients under irradiation or at equilibrium in austenite are very close at $700^{\circ} \mathrm{C}(973 \mathrm{~K}$, see Figure 4 or Table 4). Thus, under irradiation, the first right hand term in equation (9) can be replaced by a term varying with the square root of the diffusion coefficient under irradiation $\left(D^{*}\right)$ and normed by the value of the term at $700^{\circ} \mathrm{C}$ without irradiation:

$$
A_{\text {diff }} \cdot \exp \left(\frac{-E_{\text {diff }}}{\mathfrak{R} \cdot 973}\right) \cdot \sqrt{D^{*}(T) / D(973 K)}
$$

We performed the calculations for the two sets of parameters of equation (9).

\subsection{New mass transfer assessments}

Mass losses in Superphénix can be calculated according to these new equations, equation (9) for results without irradiation and equation (9) modified by equation (14) under irradiation. The results are reported in Table 1 without (columns 4 and 5 ) or with (columns 6 and 7) irradiation. Even without irradiation contribution, it is found that the mass transfer is much higher than given by Baqué's equation (3), and that it approaches the high values given by Thorley's equation (4). Under irradiation at low oxygen content $(0.7$ and $1 \mathrm{ppm})$ the mass losses are at least twice or three times higher than without irradiation. The influence of irradiation is particularly high with the second set of parameters, where the mass loss by preferential leaching is favoured. These high values for the mass loss are due to the enhanced contribution of the mild temperature surfaces (in the core) which have much larger areas than the surfaces at higher temperatures (higher than $550^{\circ} \mathrm{C}$ ). In Figure 5, the mass loss distribution in Superphénix is reported as a function of the temperature regions for the different equations at $1 \mathrm{ppm}$ of oxygen. The predicted mass losses are in good agreement with Baqué's law at temperatures higher than $600^{\circ} \mathrm{C}$. But it can be seen that most of the mass loss should occur at temperatures between $530^{\circ} \mathrm{C}$ and $570^{\circ} \mathrm{C}$, where the Baqué's law predicts almost no corrosion. It can be clearly seen from the comparison of the mass loss with or without irradiation, that the irradiation role is very important at mild temperatures (below $580^{\circ} \mathrm{C}$ ), especially for the second set of parameters (blue lines).

As it will be discussed in the following paragraph, the mass losses calculated by the new equations are likely over-estimated because no saturation of the sodium was considered, while saturation could occur at low sodium temperature or at the upper parts of the core. It should be underlined that only comparisons with the release of radionuclides on components could validate a model integrating these effects of release at mild temperatures and enhancement by irradiation. This requires a code that describes the reactor and the behaviour of the radionuclides, which is beyond the scope of this paper. 


\section{Discussion}

\subsection{Mass transfer assessment}

A key result of this study is that the mass transfer in a sodium fast reactor could be one order of magnitude underestimated or even more if low temperature corrosion and irradiation aspects are not taken into account. According to our assessments, most of the mass transfer is due to claddings corrosion between $530^{\circ} \mathrm{C}$ and $570^{\circ} \mathrm{C}$, where mass loss is hard to accurately measure, especially at low oxygen content in the sodium, and for which there are not enough consistent data available. This first attempt evidenced that a correct assessment of the mass transfer in an SFR at low oxygen content need both more precise corrosion laws at low temperatures, to part contributions from preferential leaching and general corrosion, and to take into account the effects of irradiation. However, it is difficult to separate the two contributions: preferential leaching and general corrosion, in one experiment. For instance, the use of saturated sodium to prevent preferential leaching is hard to handle in an anisothermal loop and using very low oxygen content does not allow to suppress general corrosion, as an alternative mechanism takes place in iron dissolution [8]. A method is to consider that when a depleted layer is formed and reach a steady state thickness, the corrosion rate tends asymptotically to the rate of general corrosion [23]. For example, in equation (8) Kolster considers in fact the second right hand term as representative of steady state corrosion and not specifically of general corrosion. As noted above, when the ferrite reaches a steady state thickness, the rate of formation of ferrite due the dissolution of nickel that diffuses from austenite to the sodium is equal to the rate of dissolution of ferrite by general corrosion [15]. It is likely that the steady state observed for the ferrite growth corresponds to a steady state for nickel dissolution, as nickel is the main austenitic former in the steel. However, this steady state can be reached at different times for other elements with different diffusion coefficients in austenite and ferrite. This is particularly true in sodium loop experiments, where the absence of irradiation keeps the high temperature dependence of the diffusion coefficients (unlike to what would be observed in the core).

Hence, to determine the specific rates of general corrosion, long term experiments would be necessary (during at least more than a year at temperature below $550^{\circ} \mathrm{C}$ ) to accurately determine the general corrosion rate. To enable shorter experiments, it could be interesting to use high temperature pre-exposed specimens, where a depleted layer is already formed.

If experiments were conducted to assess low temperature corrosion rates, they should be performed with relevant values of the ratio "steel surface / sodium volume" that would be representative of reactors design to take into account the saturation effect, that probably explain the particular form of the Baqué's law and the discrepancies between authors. If in an experiment, the sodium is saturated for a (rather low) given temperature, the corrosion rates might become negligible at this temperature. It might be a reason why Baqué's law neglects low temperature corrosion. Nevertheless, it should be noted that, even if it was well established by different authors that the corrosion rate decreases along an isothermal pipe (the socalled downstream effect), some of the authors were reluctant to attribute this phenomenon to the saturation of the sodium [12]. Some mentioned the poisoning effect of the surfaces by corrosion products, but no clear evidence of this effect is available. 
According to us, the results obtained from in pile claddings [14] reported in Figure 2 show that it would be necessary to take into account the sodium saturation in the mass loss equation. These observations proved that all the corroded species in the core did not deposited only on the colder parts of the components (IHX, PP) but also on the colder parts of the core and then prevent the corrosion in that place. Also, a strong "downstream effect" exists in the hot parts of the core, due to the inhibition of the cladding corrosion in the beginning of the hot zone (above $500^{\circ} \mathrm{C}$ for $\mathrm{Ni}$ and $\mathrm{Mn}$ ). As will be discussed in the next paragraph, the thickness of the ferrite layer observed by Ukai et al. is much smaller than what could be expected by the high diffusion coefficients obtained under irradiation. It could be also interpreted as a saturation of the sodium that decreases the release rate.

A consequence of the sodium enrichment in dissolved elements along the pin is that the mass transfer through the sodium boundary layer would become the limiting step. For EBR II [24], it could be considered from the examinations of the claddings that the saturation takes place at much higher temperature, about $560^{\circ} \mathrm{C}$ considering the beginning of the austenite/ferrite transformation. This can be explained by the particular conditions in this reactor: the temperatures of the claddings are higher (up to $720^{\circ} \mathrm{C}$ ) and the sodium velocity in the core is much lower, about $2 \mathrm{~m} \cdot \mathrm{s}^{-1}$. As a consequence, more corrosion takes place and limitation from diffusion in the sodium boundary layer might occur more easily.

In our calculation, the saturation effect in the hotter (or downstream) parts of the core, due to the corrosion enhancement by irradiation in the mild parts of the core, is not taken into account. Thus the mass losses reported in Table 1 calculated from Eq.(9) are probably overestimated, especially under irradiation, where large surface at mild temperatures play a major role in the release. More accurate results could only be obtained by code calculations, taking into account separate contribution for general corrosion and preferential leaching, the diffusion in the sodium boundary layer (and then sodium hydrodynamics), the saturation of the sodium, the history of the assemblies, the deposition on the cold surfaces. Moreover, comparisons with experimental results are only possible for radionuclide deposition $\left({ }^{54} \mathrm{Mn},{ }^{60} \mathrm{Co}\right.$ for which measurements have been performed), which means that their production (rate and location) and disintegration have to be taken into account. This is beyond the scope of this paper, but such a code is currently under development in our laboratory. In the mass transfer model proposed by Polley \& Skyrme [7] these different mechanisms are considered, and analogous equations are proposed for the corrosion and the deposition zones. Strictly speaking, the separation between the corrosion and deposition zones should be made for each element, by comparing its concentration in sodium to its solubility limit, rather than considering temperature zones [23] [7], and also by taking into account the activity gradients (in the steel and also in the sodium boundary limit) in the reaction rates (reverse reactions). However in the PSYCHE code developed by Japanese research groups, based on Polley \& Skyrme's model, some parts of the core are considered as a deposition zone (for dissolved alloying elements, though there is still general corrosion) and the concentration of the elements in sodium is taken in consideration [23], which is already a considerable effort to correctly assess the mass transfer.

\subsection{Effects of irradiation}


The irradiation creates a large number of point defects, and their concentrations become very high compared to equilibrium one at low temperatures. Under irradiation the bulk diffusion coefficients are much higher than at equilibrium, exhibit little temperature dependence and become (slightly) closer between ferrite and austenite. As a consequence, the irradiation must be taken into account for the mass loss calculations, in particular at low temperatures, where losses by preferential leaching (alloying elements dissolution) dominate over losses by general corrosion. The increase of the diffusion coefficients under irradiation is only slightly dependant with the dose rate.

For the modelling of mass transfer, corrected diffusion coefficients should be used, as proposed in this article, for taking into account irradiation. Still, the diffusion enhancement in ferrite layer (compared to austenite) was not taken into account in this work; but the diffusion enhancement by irradiation is so high, that it could be considered as of second order.

The ferrite thickness before reaching the steady state, where ferrite dissolution compensates its creation, is approximately related to the square root of the diffusion coefficient of nickel in austenite. At $600^{\circ} \mathrm{C}$, the value of the diffusion coefficient is multiplied by about 20 under 30 dpa. $^{-1}$. This should induce a ferrite thickness increase by $4.5(\sqrt{2} 2)$. The total contribution of the leaching due to irradiation corresponds to an average increase of the ferrite layer thickness of $6 \mu \mathrm{m}$ or $12 \mu \mathrm{m}$ respectively for the first and second set of parameters. These are much higher values than what was observed at $600^{\circ} \mathrm{C}$ by Ukai [14]: a $4 \mu \mathrm{m}$ ferrite layer in less than one year when authors observing loop samples reported ferrite layers of $2 \mu \mathrm{m}$ in a year. This should be evidence that our calculations under irradiation are overestimating the release: it might be attributed to the saturation of the sodium. It is also remarkable that under irradiation, the authors [14] mentioned that they did not observe grain boundary diffusion along the austenite grains, when it is usually the case in loop experiments: bulk diffusion dominated for in-pile claddings and it might be explained by its enhancement by irradiation. These are then qualitative proofs that the irradiation accelerates and increases the leaching corrosion process and then should be taken into account.

On the contrary, the thickness of the ferrite observed in EBR-II is much lower at $560^{\circ} \mathrm{C}-590^{\circ} \mathrm{C}$ than at $650^{\circ} \mathrm{C}$, which is contradictory with our predictions [24]. The thickness of the ferrite at $650^{\circ} \mathrm{C}$ is $4 \mu \mathrm{m}$, which is similar with the value for PHENIX pins at $600^{\circ} \mathrm{C}[14]$. In fact, as already in $\S 3.1$, it can be considered that as in EBR-II cladding temperatures are higher and sodium velocities are lower, the sodium will be more concentrated in dissolved elements and that deposition rates will be slower (lower sodium velocities induce lower Reynolds numbers and then slower transfer in the boundary layer). As a consequence, the turning point between deposition and leaching in the core could be shifted to higher temperatures: from $480^{\circ} \mathrm{C}$ in JOYO and PHENIX to $580^{\circ} \mathrm{C}$ in EBR-II. Brehm et al. underlined that low sodium velocities might hinder the low temperature corrosion regime especially for the diffusion controlled release [8]. Obviously, more observations of in-pile claddings should be needed to validate the effect of irradiation. Unfortunately, these characterizations are rare and rather difficult to perform.

A more detailed analysis would require the calculation of the diffusion coefficients (in the ferrite and austenite) under irradiation of substitutional elements: manganese, chromium, nickel and iron, to have diffusion and corrosion values related to specific 
steels of the claddings $(15-15 \mathrm{Ti} . .$.$) , to distinguish the dose rate as a function of the$ cladding location in the core...W With elements other than iron, the migration energy of the vacancies and of the interstitials would be different and then equation (10) is no more strictly valid, but must be corrected by correlation coefficients. In fact, the migration energy of vacancy will be only slightly affected by the presence of another element. On the contrary, the migration energy of the interstitial is related to the matrix deformation due to the dumbbell (couple of atoms forming the interstitial defect), which can be very large. It can be assumed that the diffusion of interstitials is lowered for elements other than iron $\left(\mathrm{Di}_{\mathrm{i}}(\mathrm{M} \neq \mathrm{Fe})<\mathrm{Di}_{\mathrm{i}}(\mathrm{Fe})\right)$. However, at steady state (for point defect concentrations under irradiation) it can be written for autodiffusion from equation (13) that:

$D_{v} \cdot C_{v}^{\text {stat }} \approx D_{i} \cdot C_{i}^{\text {stat }}$

As a consequence, for heterodiffusion, even if the term of diffusion by interstitials becomes negligible, the diffusion coefficient under irradiation will be at most divided by two, which does not affect dramatically the results (e.g. the effect of irradiation leads to a multiplication factor of 3000 at $500^{\circ} \mathrm{C}$ ).

Also, activation energy for diffusion and hence migration energy for vacancies are quite similar for main alloying elements and iron. For example, manganese, one of the most important elements for contamination has activation energy $\left(260 \mathrm{~kJ} \mathrm{~mol}^{-1}\right.$ [26]), close of the one of iron in 316 stainless steels $\left(270 \mathrm{~kJ}^{\mathrm{mol}}{ }^{-1}\right)$.

Brehm [8] suggested that a vacancy flow is produced at the ferrite/austenite interface by the preferential leaching, which might in turn enhance the diffusion in the surface depleted layer. He also noted that as the diffusion in the ferritic phase is faster than in the austenitic one, the formation of ferrite might change the diffusion flow. We tried then to compare the vacancy creation by preferential leaching as proposed by Brehm et al.[8] to the one created by irradiation. If no annihilation mechanism is considered, the maximum rate of vacancy creation is the rate of element dissolution in sodium. It can be estimated by the first right hand term of equation (9). Locally, it might correspond to a very high vacancy concentration: if it is assumed that the vacancies are within a $2 \mu \mathrm{m}$ band, it was calculated that the vacancy creation rate at $550^{\circ} \mathrm{C}$ at this point is of the same order of magnitude as the dose rate at $100 \mathrm{dpa}$. To our opinion, the vacancies are strictly speaking mostly created at the ferrite/sodium interface, which might be a strong sink for vacancies. The coral-like microstructure observed in [14] but also by other authors at temperatures above $550^{\circ} \mathrm{C}$, with cavities 3-5 $\mu \mathrm{m}$ diameter poor in nickel and manganese could be formed by the coalescence of vacancies at particular point in the surface. Moreover, this result would be in contradiction with the increased thickness of the ferrite layer observed on samples in reactor (at least by [14]) and not in sodium loop as noted above. However, the change in the diffusion coefficient between ferrite and austenite might also create a vacancy flux at this interface: a few cavities have also been observed in the ferrite layer in long term loop experiments [27]. But, if large flux of vacancies was created in the austenite, preferred grain boundary diffusion would not be observed in loop experiment samples (when it was not in in-pile samples).

Then, this vacancy creation mechanism seems important and should be rigorously addressed in further calculations. If it happens that the supersaturated vacancy concentration due to this phenomenon is not negligible by comparison to the one induced by irradiation, it would imply that the diffusion enhancement should be even observed in out-of-pile experiments and that the mass loss in these experiments would be better represented by its modified version with equation (14) than by 
equation (9). In that case, the diffusion enhancement would more steeply depend on the temperature than when considering enhancement by irradiation, as the vacancy creation depends on element depletion.

\subsection{Effects of the mass transfer}

The contamination of the circuit is one of the main concerns of the mass transfer problem in sodium circuits. The most important radionuclides in term of radiation exposure are ${ }^{54} \mathrm{Mn}$ and ${ }^{60} \mathrm{Co}$. The ${ }^{54} \mathrm{Mn}$ is both released by diffusion and general corrosion, when ${ }^{60} \mathrm{Co}$ behaviour is similar to iron and is released by general corrosion $[1,8,23]$. As a consequence of this work, it could be concluded that a better assessment of mild temperature general corrosion would be of major interest for ${ }^{60} \mathrm{Co}$, and the irradiation effect should be also accounted especially for the release of ${ }^{54} \mathrm{Mn}$. As the global release is one order of magnitude higher in this work than predicted by the ANACCONDA code, it could be also the case for ${ }^{54} \mathrm{Mn}$. It should be remembered that ${ }^{54} \mathrm{Mn}$ is produced by $(n, p)+$ reaction on ${ }^{55} \mathrm{Fe}$, and then its preferential leaching should reach more lately a lower bound compared to non active alloying elements, which flow will slow down in the depleted surface layer (the source of ${ }^{54} \mathrm{Mn}$ does not have the same gradient that $\mathrm{Mn}$ ).

Some questions could also arise about the fouling (and then loss of heat exchange) of the IHX. The deposited thickness on the IHX can be roughly estimated, supposing that $10 \%$ of the corroded species deposit on one heat exchanger and a deposit density of $4{\mathrm{~g} . \mathrm{cm}^{-3}}^{-}$. It can be assumed that a thickness above $10 \mu \mathrm{m}$ would begin to alter the heat exchange (based on thickness of the deposition and not on the wetting or other phenomena; the thickness depends in fact on the chemical and microstructural nature of the deposit). Using Baqué's equation for the release, at 1 ppm oxygen, and the above assumptions on deposition, the deposition rate is lower than $0.04 \mu \mathrm{m} \cdot \mathrm{y}^{-1}$. Considering this, the deposition rate is acceptable on the IHX whatever the oxygen content below 3 ppm, as it would not lead to deposits higher than $10 \mu \mathrm{m}$ in less than 250 years. With the present mass loss assessments (with or without irradiation), the deposition rates are much higher than previously estimated from the Baqué's law, and are not necessarily conservative as the deposition might not be uniform on the intermediate heat exchanger. A code that would account for the deposition would be welcome to insure that mass transfer would not also impact the heat transfer at the end of the plant life.

\section{Conclusion}

Mass transfer in SFR has often been considered as a consequence of the corrosion of the claddings. For this reason, the effects of corrosion at low temperatures (lower than $550^{\circ} \mathrm{C}$ ) and under irradiation were not extensively considered, as they are difficult to assess from corrosion specimens. However the contributions of mild temperature surfaces could be dominant, as they concern very large areas. In this paper, we proposed first to differentiate contributions of surface reaction (general corrosion of the metal driven by iron dissolution) and preferential leaching (diffusive release of each alloying element only depending on the diffusion coefficient in the steel) to the mass transport. It allows us to extrapolate some corrosion values even at low temperatures. 
New point defect concentrations were then calculated to take into account the effect of irradiation. New diffusion coefficients were derived and they were found to be much higher at low temperatures than coefficients considered without the irradiation influence. These results depend only slightly on the irradiation rate considered, provided reasonable values.

New kinetic laws were determined for corrosion release, with or without irradiation. As an application, the mass loss in one year in Superphénix was assessed. It was found that the mass transfer might be an order of magnitude higher with these new assumptions compared to calculations with previous kinetic laws. Depending on the set of parameters, the irradiation might contribute in a large extent to the increase. However, it is likely that these results are conservative, as no saturation effect is taken into account in sodium.

It is believed that a correct estimation of the mass transfer and contamination in a sodium fast reactor could only be performed by a code taking into account the following elements: correct and separate low temperature correlations for general corrosion and preferential leaching, irradiation and sodium saturation.

This first approach highlights the importance of these elements, and should help to improve the mass transfer evaluation for the new sodium fast reactors. It also highlights a need for experimental results as, for instance, long term measurements at low temperature of core materials.

\section{Nomenclature}

Most of the symbols used in the text are defined in Table 5. Units are generally not in SI as most of the release equations were obtained in the 1970's.

\begin{tabular}{|c|c|c|}
\hline Symbol & Significance & Units \\
\hline $\mathrm{t}$ & time & $\mathrm{s}$ \\
\hline$t_{B}$ & Time, thousands hours & $\mathrm{h}$ \\
\hline S & Specific mass loss in sodium & g.cm-2 $\cdot \mathrm{y}^{-1}$ \\
\hline$S_{B}$ & Specific mass loss in sodium & $\mu \mathrm{g} \cdot \mathrm{mm}^{-2}$ \\
\hline$\rho$ & density & g. $\mathrm{cm}^{-3}$ \\
\hline C & Relative weight concentration & $g . g^{-1}$ \\
\hline $\mathrm{D}$ & Diffusion coefficient & $\mathrm{cm}^{2} \cdot \mathrm{s}^{-1}$ \\
\hline [O] & Oxygen concentration in sodium & ppm \\
\hline $\mathrm{v}$ & Sodium velocity & m.s. ${ }^{-1}$ \\
\hline $\mathrm{T}$ & Temperature & $\mathrm{K}$ \\
\hline$\theta$ & Temperature & ${ }^{\circ} \mathrm{C}$ \\
\hline $\mathscr{K}$ & Perfect gas constant & $\mathrm{J}^{\mathrm{K}} \mathrm{K}^{-1} \cdot \mathrm{mol}^{-1}$ \\
\hline$E_{A}$ & Activation energy & ${\mathrm{J} . \mathrm{mol}^{-1}}^{-1}$ \\
\hline $\mathrm{G}$ & Damage rate under irradiation & $\mathrm{cm}^{-3} \cdot \mathrm{s}^{-1}$ \\
\hline $\mathrm{B}$ & Point defect recombination rate & $\mathrm{S}^{-1}$ \\
\hline $\mathrm{kd}_{\mathrm{d}}$ & Sink strength for defect d & $\mathrm{cm}^{-2}$ \\
\hline $\mathrm{R}$ & Average distance between dislocations & $\mathrm{cm}$ \\
\hline
\end{tabular}

Table 5 : nomenclature of the symbols of the equations in the text.

\section{Appendix}

Calculation of characteristic times, concentration and diffusion coefficient under irradiation. 


\section{Formation and migration of point defects}

The vacancy equilibrium concentration $\mathrm{n}_{\mathrm{e}} / \mathrm{N}$ ( $\mathrm{n}_{\mathrm{e}}$ number of vacancy at equilibrium and $\mathrm{N}$ number of atoms per volume unit) is expressed from the formation energy $E_{v}^{f}$ and entropy $S_{v}^{f}$ of a vacancy:

$$
n_{e} / N=\exp \left(\frac{-\Delta E_{v}^{f}}{\Re \cdot T}+\frac{\Delta S_{v}^{f}}{\Re}\right)
$$

At $1184 \mathrm{~K}$, equilibrium temperature between gamma and alpha iron $\left(T_{\alpha \gamma}\right)$, Schaefer [28] found the following equilibrium vacancy concentration $C^{E} v=7.7 \times 10^{-7}$.

By writing the ratio between equation (A1) at a given temperature T and at $1184 \mathrm{~K}$, the vacancy concentration at equilibrium at a given $T$ temperature is given by:

$$
C_{v}^{E}=7.7 \cdot 10^{-7} \cdot \exp \left(-\Delta E_{v}^{f} \cdot \frac{1184-T}{R \cdot T .1184}\right)
$$

This equation applies both for alpha and gamma iron, provided that respective formation energies for the vacancies are used.

Data needed for the calculation of point defect equilibrium concentration and point defect diffusion are reported in Table 6. The values in $\alpha$ iron are taken from [29] and from Pokor et al. [30] for both point defects in SS304 (being also valid for 316 and 316 Ti steels).

Relationship (A2) was also used for the calculation of vacancy concentration in stainless steel, using vacancy energy of formation given by Pokor et al. [30] for type 316 steel. This yields a vacancy concentration of $5.0 \times 10^{-13}$ at $440^{\circ} \mathrm{C}$, when $4.9 \times 10^{-12}$ is given by Stanley et al. [31], which could be considered as reasonable agreement, regarding the rough assumptions made for this kind of calculation. Values for vacancies are in good agreement with those used by Stoller [32] or Doan [33] for the modelling of point defect diffusion, though some variations for defect migration energies are sometimes proposed by these authors.

\section{Calculation of recombination rate and sink strength}

A steady state solution must be obtained for equation (12) for a given point defect formation rate $\mathrm{G}$. First, all the terms of the equation must be calculated.

The recombination rate $B$ is proportional to $D_{i}+D_{v}$, diffusion coefficients for interstitials and vacancies respectively [25].

$$
B=\frac{4 \cdot \pi \cdot r_{i v} \cdot\left(D_{i}+D_{v}\right)}{\Omega}
$$

where $r_{i v}$ recombination radius and $\Omega$ the atomic volume. The value of the recombination radius $r_{i v}$ was taken from Meslin [29], as $0.65 \mathrm{~nm}$.

The dislocations are the main sinks to be considered in most materials. Following a classical analysis by Barbu and Martin [34], the defects are attracted by the stress field generated by the sinks. Defining the sinks strength for the dislocation as $k^{2} i d$, the sink annihilation term can be written as :

$\left(\frac{\partial C_{i}}{\partial t}\right)_{\text {dislocation }}=-k_{i d}^{2} \cdot D_{i} \cdot\left(C_{i}-C_{i e}\right)$

where $C_{i}$ is the concentration far from the dislocation, $C_{i e}$ interstitial concentration at equilibrium and $D_{i}$ is the coefficient of diffusion of the defects. 
The sink strength for a dislocation is given by:

$$
k_{i d}^{2}=\rho_{d} \cdot Z_{i d}
$$

where $\rho_{d}$ is the density of dislocations and $Z_{\text {id }}$ represents the interaction of the defects with the dislocation. A recent and further analysis of the sink strength is given in [33].

$$
Z_{i d}=\frac{2 \cdot \pi}{\ln \left(2 \cdot R / L_{i d}\right)}
$$

$R$ is the average distance between dislocations:

$$
R=\left(\pi \cdot \rho_{d}\right)^{-1 / 2}
$$

and $L_{d d}$ is an average term for the interaction energy between the defect and the dislocation :

$$
L_{d d}=\frac{\mu \cdot b \cdot(1+v) \cdot \Delta V_{d}}{3 \cdot \pi \cdot(1-v) \cdot k \cdot T}
$$

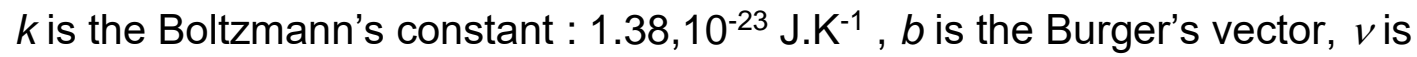
Poisson's modulus and $\Delta V_{d}$ is the relaxation volume of the defect.

Dislocation density in a metal varies from $10^{7}$ to $10^{11}$ dislocations $/ \mathrm{cm}^{2}$. A classical dislocation density of $10^{8}$ dislocations $/ \mathrm{cm}^{2}$ have been chosen, corresponding to an average distance between dislocations of $R_{d}=0.56 \mu \mathrm{m}$.

The calculations of $D, Z, R$ and $L$ will allow us to calculate the flow of defects on the dislocation.

In Table 6, the data needed for the calculation of L, Z, B and $k_{d}$ are reported and examples of calculated values are reported in Table 7.

\begin{tabular}{|l|l|}
\hline$\alpha$ iron $E_{v}^{f} ; E^{m_{v}}$ & $212.3 ; 64.6 \mathrm{~kJ}$ \\
\hline$\alpha$ iron $E_{i}^{f} ; E^{m_{i}}$ & $415 ; 28.9 \mathrm{~kJ}$ \\
\hline$\alpha$ iron $D_{v 0} ; D_{i 0}$ & $8.2 \times 10^{-3} \mathrm{~cm}^{2} . \mathrm{s}^{-1}$ \\
\hline$S S 304 E_{v}^{f} ; E^{m_{v}}$ & $164 ; 130 \mathrm{~kJ}$ \\
\hline$S S 304 \mathrm{E}_{i}$ & $41.5 \mathrm{~kJ}$ \\
\hline$S S 304 D_{v 0} ; D_{i 0}$ & $0.6 ; 1 \times 10^{-3} \mathrm{~cm}^{2} . \mathrm{s}^{-1}$ \\
\hline$\alpha$ iron $\mu$ & $7.58 \times 10^{10} \mathrm{~Pa}$ \\
\hline$S S 304 \mu$ & $6.56 \times 10^{10} \mathrm{~Pa}$ \\
\hline$r_{i v}$ & $0.65 \mathrm{~nm}$ \\
\hline$\rho$ & $10^{8} \mathrm{~cm} \cdot \mathrm{cm}^{-3}$ \\
\hline$\Delta V_{v} ; \Delta V_{i}$ & $13 \times 10^{-3} ; 2.6 \times 10^{-3} \mathrm{~nm}^{3}$ \\
\hline$b$ & $0.2 \mathrm{~nm}$ \\
\hline$v$ & 0.28 \\
\hline
\end{tabular}

Table 6 : Parameters values used in the irradiation calculation

Comparing the sink strength obtained by these calculations and the constant values proposed by Meslin [29] for alpha iron, 1 for vacancies and 1.1 for interstitials, the results are close. 


\begin{tabular}{|c|c|c|c|c|c|}
\hline$\alpha \mathrm{Fe}$ & $L(m)$ & Z & $\mathrm{k}^{2}\left(\mathrm{~cm}^{-2}\right)$ & $B\left(s^{-1}\right)$ & $\mathrm{D}\left(\mathrm{cm}^{2} \cdot \mathrm{s}^{-1}\right)$ \\
\hline $\begin{array}{l}\text { Interstitials } \\
350^{\circ} \mathrm{C}\end{array}$ & $8.6 \times 10^{-10}$ & 0.66 & $6.6 \times 10^{5}$ & $3.3 \times 10^{12}$ & $3.1 \times 10^{-5}$ \\
\hline $\begin{array}{l}\text { Vacancies } \\
350^{\circ} \mathrm{C}\end{array}$ & $4.3 \times 10^{-9}$ & 0.80 & $8.0 \times 10^{5}$ & $3.3 \times 10^{12}$ & $3.1 \times 10^{-8}$ \\
\hline $\begin{array}{l}\text { Interstitials } \\
550^{\circ} \mathrm{C}\end{array}$ & $6.5 \times 10^{-10}$ & 0.64 & $6.4 \times 10^{5}$ & $8.4 \times 10^{12}$ & $1.2 \times 10^{-4}$ \\
\hline $\begin{array}{l}\text { Vacancies } \\
550^{\circ} \mathrm{C}\end{array}$ & $3.3 \times 10^{-9}$ & 0.77 & $7.7 \times 10^{5}$ & $8.4 \times 10^{12}$ & $6.4 \times 10^{-7}$ \\
\hline SS 304 & $\mathrm{~L}(\mathrm{~m})$ & $\bar{Z}$ & $\mathrm{k}^{2}\left(\mathrm{~cm}^{-2}\right)$ & $\mathrm{B}\left(\mathrm{s}^{-1}\right)$ & $\mathrm{D}\left(\mathrm{cm}^{2} \cdot \mathrm{s}^{-1}\right)$ \\
\hline $\begin{array}{l}\text { Interstitials } \\
350^{\circ} \mathrm{C}\end{array}$ & $7.5 \times 10^{-10}$ & 0.65 & $6.5 \times 10^{5}$ & $2.3 \times 10^{10}$ & $3.3 \times 10^{-7}$ \\
\hline $\begin{array}{l}\text { Vacancies } \\
350^{\circ} \mathrm{C}\end{array}$ & $3.7 \times 10^{-9}$ & 0.78 & $7.8 \times 10^{5}$ & $2.3 \times 10^{10}$ & $7.1 \times 10^{-12}$ \\
\hline $\begin{array}{l}\text { Interstitials } \\
550^{\circ} \mathrm{C}\end{array}$ & $5.6 \times 10^{-10}$ & 0.63 & $6.4 \times 10^{5}$ & $1.6 \times 10^{11}$ & $2.3 \times 10^{-6}$ \\
\hline $\begin{array}{l}\text { Vacancies } \\
550^{\circ} \mathrm{C}\end{array}$ & $2.8 \times 10^{-9}$ & 0.76 & $7.6 \times 10^{5}$ & $1.6 \times 10^{11}$ & $3.2 \times 10^{-9}$ \\
\hline
\end{tabular}

Table 7 : Parameters for the sink strength determination calculated at $350^{\circ} \mathrm{C}$ and $550^{\circ} \mathrm{C}$ for interstitials and vacancies in alpha iron and 304 stainless steels.

Four characteristic times as defined by Sizmann [25] are reported in Table 8, as well as the values calculated at $400^{\circ} \mathrm{C}$ and $600^{\circ} \mathrm{C}$ in alpha iron and 304 stainless steel in the case of a 100 dpa. $\mathrm{y}^{-1}$ irradiation flow rate. The inequality $\tau_{1}<\left(\tau_{2} \cdot \tau_{3}\right)^{1 / 2}$ defines a low temperature case.

\begin{tabular}{|l|l|c|c|c|c|}
\hline Time & Formula & $\begin{array}{c}\text { Alpha iron } \\
350^{\circ} \mathrm{C}\end{array}$ & $\begin{array}{c}\text { Alpha iron } \\
550^{\circ} \mathrm{C}\end{array}$ & $\begin{array}{c}\text { SS } 304 \\
350^{\circ} \mathrm{C}\end{array}$ & $\begin{array}{c}\text { SS } 304 \\
550^{\circ} \mathrm{C}\end{array}$ \\
\hline$\tau_{1}$ & $(G \cdot B)^{-1 / 2}$ & $7.0 \times 10^{-4} \mathrm{~s}$ & $3.5 \times 10^{-4} \mathrm{~s}$ & $6.8 \times 10^{-3} \mathrm{~s}$ & $2.6 \times 10^{-3} \mathrm{~s}$ \\
\hline$\tau 2$ & $1 /\left(k_{i}^{2} \cdot C_{i}\right)$ & $4.9 \times 10^{-2} \mathrm{~s}$ & $1.3 \times 10^{-4} \mathrm{~s}$ & $4.7 \mathrm{~s}$ & $6.8 \times 10^{-1} \mathrm{~s}$ \\
\hline$\tau_{3}$ & $1 /\left(k_{v}^{2} \cdot C_{v}\right)$ & $40 \mathrm{~s}$ & $20 \mathrm{~s}$ & $1.8 \times 10^{5}$ & $408 \mathrm{~s}$ \\
\hline$\tau_{4}$ & $\tau_{1}^{2} / \tau_{2}$ & $1.0 \times 10^{-5} \mathrm{~s}$ & $9.7 \times 10^{-6} \mathrm{~s}$ & $9.9 \times 10^{-6} \mathrm{~s}$ & $9.6 \times 10^{-6} \mathrm{~s}$ \\
\hline & $\tau_{1} /\left(\tau_{2} \cdot \tau_{3}\right)^{1 / 2}$ & $5.0 \times 10^{-4}$ & $2.2 \times 10^{-3}$ & $7.5 \times 10^{-6}$ & $1.5 \times 10^{-4}$ \\
\hline
\end{tabular}

Table 8 : Characteristic times as defined by Sizmann [25] for stationary concentrations of interstitials or vacancies in alpha iron or 304 stainless steel.

In each case, the characteristic times are very low, steady state is reached in the very first time of irradiation, and the solution corresponds to a low temperature one, where recombination of the defects dominates.

\section{Acknowledgements}

The author thanks A. Barbu (CEA/DEN/DMN) for fruitful discussion on irradiation effects and G. Rodriguez, Th. Gilardi and Ch. Latgé (CEA/DEN/DTN) for careful reading and suggestions. 


\section{References}

1. Thorley, A. W.; Michaille, P. Fission and corrosion product behaviour in liquid metal fast breeder reactors (LMFBRs); IAEA-TECDOC-687; Vienna, 1993.

2. Zhang, J.; Hosemann, P.; Maloy, S., Models of liquid metal corrosion. Journal of Nuclear Materials 2010, 404, (1), 82-96.

3. Brehm, W. F. In Transport of radioactive material in liquid sodium, Material Behavior and Physical Chemistry in Liquid Metal Systems 2, Karlsruhe, 24-26 mars, 1993, Edited by: Borgstedt, H. U., Plenum Press, 1995, pp 1-8 (1993).

4. $\quad$ Clerc, R.; Guidez, J.; Maux, P.; Michaille, P.; Misraki, J.; Miska, D. In The french experience concerning the contamination of the LMFBRs, Fission and corrosion product behaviour in Primary Circuit of LMFBRs, IWGFR/64, Karlsruhe, RFA, 5-8 May 1987, Edited by: Feuerstein, H.; Thorley, A. W., KfK 4279, pp 93-186 (1987).

5. Lizawa, K.; Chatani, K.; Ito, K.; Suzuki, S.; Akutsu, M.; Kinjo, K. In Transport of radioactive corrosion products in primary systems of a sodium cooled fast reactor, Material Behavior and Physical Chemistry in Liquid Metal Systems 2, Karlsruhe, 2426 mars, 1993, Edited by: Borgstedt, H. U., Plenum Press, 1995, pp 9-26 (1993). 6. Robin, J.-C.; Masse, F. In Estimation of deposited activity on liquid metal reactors primary circuits, ENC'98, Nice, 25-28 oct, 1998, Edited by: World Nuclear Congress and Expo, pp 75-79 (1998).

7. Polley, M. V.; Skyrme, G., An analysis of radioactive corrosion product transfer in sodium loop systems. Journal of Nuclear Materials 1978, 75, 226-237.

8. Brehm, W. F.; Anantatmula, R. P. In Corrosion product release into sodium from austenitic stainless steel, Material Behavior and Physical Chemistry in Liquid Metal Systems, Karlsruhe, 24-26 mars, 1981, Edited by: Borgstedt, H. U., Plenum Press, pp 193-204 (1982).

9. Keeton, A. R.; Bagnall, C. In Factors that affect corrosion in sodium, Second International Conference on Liquid Metal Technology in Energy Production, Richland, Avril 20-24, 1980, Edited by: Dahlke, J. M., IAEA Conf-800401-P1 UC-79A, pp 7.187.25 (1980).

10. Masse, F.; Rouvière, G. In Activation, corrosion and contamination in fast breeder reactors. Validation of models with experimental data, Material Behavior and Physical Chemistry in Liquid Metal Systems 2, Karlsruhe, 24-26 mars, 1993, Edited by: Borgstedt, H. U., Plenum Press, 1995, pp 35-46 (1993).

11. Weeks, J. R.; Isaacs, H. S., Corrosion and deposition of steel and nickel base alloys in liquid sodium. Advances in corrosion science and Technology 1973, 3, 1-66. 12. Thorley, A. W.; Blundell, A.; Bardsley, J. A.; Lloyd, R. In Mass transfer behaviour of stainless steels in flowing sodium environments at different oxygen levels, Fourth International Conference on Liquid Metal Technology in Energy Production, Avignon, Octobre 17-21, 1988, Edited by: Dahlke, J. M., SFEN, pp 532.1532.13 (1988).

13. Sridharan, R.; Gnanasekaran, T.; Periaswani, G.; Mathews, C. K. In Thermochemistry of Na-Fe-O system and its relevance to corrosion of steels in sodium, Material Behavior and Physical Chemistry in Liquid Metal Systems 2, Karlsruhe, 24-26 mars, 1993, Edited by: Borgstedt, H. U., Plenum Press, pp 269-277 (1995).

14. Ukai, S.; Yoshida, E.; Enokido, Y.; Nihei, I., Quantitative characterization on dissolution and deposition behavior of SUS316 stainless steel cladding constituents 
under flowing sodium in fast reactors. In Materials for nuclear reactor core application, BNES: London, 1987; Vol. 1, pp 341-348.

15. Anno, J. W.; Walowit, J. A., Analysis of corrosion of stainless steel in sodium and high radiation environment. Nuclear Technology 1971, 10, 67-75.

16. Clerc, R.; Guidez, J.; Michaille, P.; Misraki, J. In Bilan des mesures de contamination effectuées à Phénix au 1er avril 1987, Fission and corrosion product behaviour in Primary Circuit of LMFBRs, IWGFR/64, Karlsruhe, RFA, 5-8 May 1987, Edited by: Feuerstein, H.; Thorley, A. W., KfK 4279, pp 141-185 (1987).

17. Eichelberger, R. L. The solubility of oxygen in sodium : a recommanded expression:; AEC 12685; A.I. Canoga Park (California): 1968.

18. Furukawa, T.; Kato, S.; Yoshida, E., Compatibility of FBR materials with sodium. Journal of Nuclear Materials 2009, 392, (2), 249-254.

19. Borgstedt, H. U.; Mathews, C. K., Applied Chemistry of the Alkali Metals. Plenum Press: New York, 1987.

20. Baqué, P. unpublished results; 1980.

21. Kolster, B. H. In The influence of sodium conditions on the rate for dissolution and metal/oxygen reaction of AISI 316 in liquid sodium, Second International Conference on Liquid Metal Technology in Energy Production, Richland, Avril 20-24, 1980, Edited by: Dahlke, J. M., IAEA Conf-800401-P1 UC-79A, pp 7.53-7.61 (1980). 22. Borgstedt, H. U. In Experimental corrosion results compared to calculated corrosion rates from different models, Second International Conference on Liquid Metal Technology in Energy Production, Richland, Avril 20-24, 1980, Edited by: Dahlke, J. M., IAEA Conf-800401-P1 UC-79A, pp 7.1-7.10 (1980).

23. Lizawa, K.; Suzuki, S.; Tamura, M.; Seki, S.; Hikichi, T. In Study on radioactive corrosion products behaviour in primary circuits of JOYO, Fission and corrosion product behaviour in Primary Circuit of LMFBRs, IWGFR/64, Karlsruhe, RFA, 5-8 May 1987, Edited by: Feuerstein, H.; Thorley, A. W., KfK 4279, pp 227-269 (1987). 24. Weber, J. W. In In reactor corrosion behavior of stainless steel in high temperature sodium, International Conference on Liquid Metal Technology in Energy Production, Champion, USA, Edited by: Cooper, M. H., ASME, pp 378-385 (1976). 25. Sizmann, R., The effect of radiation upon diffusion in metals. Journal of Nuclear Materials 1978, 69\&70, 386-412.

26. Smith, A. F.; Hales, R., Diffusion of manganese in type 316 austenitic stainless steel. Metal Science 1975, 9, 181-184.

27. Ganesan, V.; Ganesan, V.; Borgstedt, H. U., Analysis of CREVONA sodium loop material. Journal of Nuclear Materials 2003, 312, (2-3), 174-180.

28. Schaefer, H. E.; Maier, K.; Weller, M.; Herlach, D., Vacancy formation in iron investigated by positron annihilation in thermal equilibrium. Scripta Metallurgica 1977, 11, 803-809.

29. Meslin, E.; Barbu, A.; Boulanger, L.; Radiguet, B.; Pareige, P.; Arakawa, K.; Fu, C. C., Cluster-dynamics modelling of defects in [alpha]-iron under cascade damage conditions. Journal of Nuclear Materials 2008, 382, (2-3), 190-196.

30. Pokor, C.; Brechet, Y.; Dubuisson, P.; Massoud, J. P.; Barbu, A., Irradiation damage in 304 and 316 stainless steels: experimental investigation and modeling. Part I: Evolution of the microstructure. Journal of Nuclear Materials 2004, 326, (1), 19-29.

31. Stanley, J. T.; Cost, J. R., Irradiation enhanced short range ordering in austenitic stainless steel. Journal of Physics F (Metal Physics) 1984, 14, (8), 18011810. 
32. Stoller, R. E. In The role of point defect clusters in reactor pressure vessel embrittlement, 6th symposium on environmental degradation of materials in nuclear power systems - Water reactor (TMS), Edited by: pp 747-754 (1994).

33. Doan, N. V.; Martin, G., Elimination of irradiation point defects in crystalline solids: Sink strengths. Physical Review B 2003, 67, (13).

34. Barbu, A.; Martin, G., Radiation effect in metals and alloys. Solid State Phenomena 1993, 30-31: Materials under irradiation, 179-228. 